\title{
Relationship between Family Caregivers' Attitudes toward Mental Illness and Psychotropic Medications, and Patients' Adherence to Medication
}

\section{Regimen}

\author{
Marwa Abd El-Gawad Ahmed Mousa, Lecturer \\ Psychiatric Nursing and Mental Health, Faculty of Nursing, Alexandria University
}

\begin{abstract}
Medication nonadherence is a particular challenge in psychiatric nursing practice. Enhancing adherence should involve not only assessing patients' attitudes toward medication, but also their family caregivers' attitudes toward mental illness and its medication regimens. Objective: This study aimed to elicit family caregivers' attitudes toward mental illness and psychotropic medications, assess the degree of outpatients' adherence to psychotropic medications regimen, and investigate the relationship between caregivers' attitudes, and patients' adherence. Setting: The study was conducted in the outpatient clinic of ElMaamoura Hospital for Psychiatric Medicine, Alexandria. Subjects: They comprised 150 family caregivers and 150 of outpatients with psychotic disorders. Tools: Four tools were used to collect the data; a Socio-Demographic, Clinical and Caregiving-Related Data Structured Interview Schedule, Family Attitude toward Mental Illness (FAMI) Scale, Family Attitude toward Psychotropic Medications (FAPM) Scale, and Adherence to Psychotropic Medications Structured Interview Schedule. Results: It was revealed that the majority of caregivers hold positive attitude towards mental illness, most of them demonstrated positive attitude towards psychotropics, and around two thirds of outpatients were adherents to the medication regimen. Statistically significant relationships were evident between caregivers' attitude toward both mental illness and its medications, and patient's adherence. Conclusion: Patients' adherence to medication regimen is significantly related to their family caregivers' attitudes toward mental illness and its medications. Recommendations: Incorporating the assessment of family caregivers' attitudes toward mental illness and medications into the routine psychiatric nursing practice, and involving family caregivers while implementing adherence-enhancing interventions are essential.
\end{abstract}

Kevwords: Adherence; Family Caregivers; Attitudes; Mental illness; Psychotropic medications.

\section{Introduction}

Remarkable advances in psychopharmacologic agents greatly influence the psychiatric clinical outcomes, and they are now considered the most effective treatment for psychotic disorders $^{(1)}$. Indeed, research evidences indicate that using psychotropic medications as prescribed has major beneficial effects for mental illness sufferers. These medications not only provide patients with a relief from debilitating psychotic symptoms, but also act as a defense against relapse. Patients can then be integrated into the community, and maintain independent living conditions. In spite of these advantages, many patients do not actually benefit from them due to low adherence to medication regimens ${ }^{(2-4)}$.

Adherence is defined as the patient's willingness and ability to abide by the recommended therapeutic regimen. It is the extent to which the patient is conforming to the prescribed medication dosage, dose scheduling, and method of administration $^{(5,6)}$. Consequently, the patient who follows the treatment schedules, agrees with pharmacotherapeutic recommendations and takes medications exactly as prescribed is considered adherent ${ }^{(7)}$. On the other hand, nonadherence could be defined as a failure 
to enter a treatment program, intentional and premature termination of a prescribed medication regimen, and/or incomplete implementation of therapeutic instructions. The patient who is not taking the prescribed medications at all, missing some of the prescribed doses, taking correct doses at incorrect times, taking the incorrect doses, taking medications other than those prescribed, taking medicines of inadvertent combinations, and/or discontinuing the course of medication early can be described as nonadherent ${ }^{(4,8,9)}$.

It was estimated that up to $93 \%$ of patients with different psychotic disorders are nonadherents to their medication regimens ${ }^{(9,10,11)}$. Failure to adhere to prescribed medication regimens has been shown to be a significant barrier to effective long-term treatment of chronic psychotic disorders and has a substantial impact on the disease progression. Severe psychopathology, relapse, psychiatric rehospitalization, impaired psychosocial functioning, and increased dependency and disability, are among the serious consequences of nonadherence. These in turn increase the burden on family caregivers, the health care system and the society as well ${ }^{(7,12,13)}$.

Previous studies have investigated several factors which could influence a patient's decision to adhere or not adhere to prescribed psychotropic medications. Patients' attitudes toward both mental illness and psychotropic medications are among these factors ${ }^{(12,14,15)}$. However, this traditional focus on the relationship between patients' adherence to medications and such attitudes is no longer enough. A better understanding of medication adherence should involve not only assessing patients' attitudes toward medication, but also their family caregivers' attitudes toward patient's mental illness and its medication regimens ${ }^{(7)}$. The renewed interest in the role of the family attitudes in the treatment, prognosis and management of their patients' mental disorders is based on the assumption that attitudes and beliefs within the individual's social environment might play a role in explaining successful help-seeking behaviors, such as medication adherence. At the same time, it was thought that patients whose families are ambivalent about the treatment are at increased risk of medication nonadherence ${ }^{(16)}$. That is why family caregivers' views on this issue warrant more exploration.

In order to study the relationship between family caregivers' attitudes toward mental illness and psychotropics and their patients' adherence, it is crucial to emphasize the role of the family in the care of patients with psychotic disorders. The Egyptian community mental health services are unfortunately inadequate allover the country $^{(17)}$. Thus, caring for patients with mental illness in the community relies heavily on the informal care provided by their family members who are considered to be the "frontline caregivers" ${ }^{(18)}$. On that base, it was acknowledged that the patients' adherence to psychotropics can be improved by working with the family ${ }^{(7)}$. In spite of this and despite the greater involvement of families in the care of patients with different mental illnesses, their attitudes are less likely to be recognized when evaluating patients' adherence to the prescribed medications ${ }^{(19)}$.

Presently, medication nonadherence is a particular challenge in psychiatric nursing practice $^{(2,3)}$. The psychiatric nurse's responsibility for facilitating and enhancing adherence may require an in-depth assessment and understanding of the family caregivers' attitudes toward mental illness and psychotropic medications as well as the relationship of such attitudes with patients' adherence. If this relationship is determined, the adherence process can be improved in two ways. First, when caregivers' negative attitudes are elicited, they can be modified effectively through developing the appropriate family intervention programs. Second, psychiatric nurses can formulate a strong collaboration with caregivers who have positive attitude toward mental illness and medications to be 
involved in the patients' care plan to enrich adherence enhancing nursing interventions.

\section{Aims of the Study}

This study aimed to:

1- Elicit family caregivers' attitudes toward mental illness and psychotropic medications.

2- Assess the degree of adherence to psychotropic medications regimen among outpatients with psychotic disorders.

3- Investigate the relationship between such family caregivers' attitudes, and patients' adherence to psychotropic medications regimen.

\section{Research Questions:}

1- What are family caregivers' attitudes toward mental illness and psychotropic medications?

2- What is the degree of adherence to psychotropic medications regimen among outpatients with psychotic disorders?

3- What is the relationship between such family caregivers' attitudes, and patients' adherence to psychotropic medications regimen?

\section{Materials and Method}

\section{Materials}

Design: This study followed a descriptive correlational design.

Setting: The current study was conducted in the outpatient clinic of El-Maamoura Hospital for Psychiatric Medicine in Alexandria which is affiliated to the Ministry of Health and Population. The hospital serves three governorates, namely; Alexandria, Matrouh and El-Beheira. The psychiatric outpatient clinic provides free treatment services for all patients suffering from mental illness and substance dependence. The services include psychiatric examination, diagnosis, dispensing necessary medications, follow up and referral of the outpatients to the inpatient wards when necessary. The outpatient clinic works six days a week (Saturday through Thursday), from 9:00 am to $1: 00 \mathrm{pm}$.

Subjects: The Epi info 7 program was used to estimate the sample size based on using $10 \%$ acceptable error, $99 \%$ confidence coefficient, $60 \%$ expected frequency and population size of 1440 patients (the number of patients with psychotic disorders regularly visiting the outpatient clinic and accompanied by at least one family caregiver over a period of three months according to the outpatient clinic's records).

The program revealed the minimum sample size to be 144 subjects, so it was decided to recruit:

1. One hundred and fifty family caregivers of those accompanying the outpatients with the following inclusion criteria:

1) Living with the patient in the same household.

2) Currently engaging in physical, emotional, and/or financial caregiving, i.e., being the patient's parent, sibling, spouse and/or son or daughter.

3) Aged 18 years or older.

2. A convenient sample of 150 outpatients diagnosed with psychotic disorders for at least six months, and able to communicate in a coherent and relevant manner.

Tools: The following four tools were used to collect the data:

Tool I: A Socio-Demographic, Clinical and Caregiving-Related Data Structured Interview Schedule

This interview schedule was developed by the researcher to elicit data about the general socio-demographic, clinical and caregiving-related characteristics of both patients and their family caregivers. It includes two parts: 
o Part (1): This part covers patient's sociodemographic data such as sex, age, marital status and educational level, and clinical characteristics, e.g., psychiatric diagnosis, duration of illness, number of previous psychiatric hospitalization, and reason for visiting the outpatient clinic.

o Part (2): This part is concerned with family caregivers' socio-demographic, clinical and caregiving-related data. It covers socio-demographic data such as kinship to the patient, sex, age, marital status and educational level, and clinical and caregiving characteristics such as family history of mental illness, duration of caregiving role, and reasons of becoming a caregiver.

\section{Tool II: Family Attitude toward Mental Illness (FAMI) Scale}

The FAMI scale was constructed by the researcher after a thorough review of the related literature to elicit families' attitude toward mental illness ${ }^{(18,20-22)}$. It comprises 20 statements such as "patients with mental illness are usually unpredictable and dangerous", "they can become productive members of the society", and "mental illness is an illness like any other physical illness".

Family caregivers are asked to rate their responses to the statements on a threepoint Likert scale, with 0 indicating "no", 1 indicating "neutral/do not know" and 2 indicating "yes". The total score ranges from 0 to 40, with higher scores reflecting a more positive attitude toward mental illness. A score of 0-20 means that the family caregiver has a negative attitude, while a score of 21-40 reflects an inclination towards positive attitude mental illness.

\section{Tool III: Family Attitude toward} Psychotropic Medications (FAPM) Scale

This scale was designed by the researcher after an extensive review of the literature to capture families' attitude toward psychotropic medications through gaining some understanding of what they think about medications which their relative patients are taking ${ }^{(7,11,23-25)}$. The FAPM scale has 20 statements rated on a threepoint Likert scale, with 0 denoting "disagree", 1 denoting "neutral/do not know" and 2 denoting "agree".

Statements, such as "continued taking psychotropic medications can minimize patient's relapse", "medications may cause addiction", and "long-term use of medications can be dangerous", are examples of the scale content.

The total score for the scale ranges from 0 to 40, with higher scores indicating more positive attitude toward psychotropic medications. Family caregivers who score from 0 to 20 are considered as having a negative attitude, while those caregivers with a score ranging from 21 to 40 are considered as having a positive attitude toward psychotropic medications.

Tool IV: Adherence to Psychotropic Medications Structured Interview $\underline{\text { Schedule }}$

For the purpose of the current study, this tool was developed by the researcher after reviewing the related literature ${ }^{(8-10,12,15)}$ to assess patients' adherence to psychotropic medication regimens.

Patients are asked through an open ended question to describe the medication taking behavior during the last month. The judgment is made based on the previous adherence-related studies ${ }^{(26-29)}$. Accordingly,

- Patients are considered as medication adherents if they take all prescribed doses of medications regularly at the correct time by themselves or when reminded by the caregiver and/or accept and do not resist when asked to take medications.

- Patients are considered as medication nonadherents if they refuse all or only some types of oral or depot medications, take the medication only when it is compulsory, require persuasion to accept the medication, increase or decrease the prescribed doses and frequency of medication 
regimen by themselves and/or take it occasionally for specific symptoms and then discontinue the prescribed regimen by themselves when symptoms relieve.

Classification of patients as either adherents or nonadherents to their medication regimens is done on the basis of both patients' and their family caregivers' self-report descriptions for the patient's adherence over a period of the past month. If the patient's and family caregiver's descriptions are inconsistent, only family caregivers' reports are taken into account.

\section{Method}

- Official written permissions to conduct the study were obtained from the responsible authorities. These included the General Secretariat for Mental Health and Population in Cairo, and the director of El-Maamoura Hospital for Psychiatric Medicine in Alexandria.

- Tools I, II, III and IV were developed by the researcher after a careful reviewing of the related literature.

- A jury composed of five experts in the fields of psychiatric nursing and medicine was consulted to examine the content validity of the study tools. All tools proved to be valid.

- A pilot study was carried out on 15 patients of those attending the outpatient clinic and 15 family caregivers of those patients who meet the criteria of the study sample. According to the results of the pilot study, few modifications were done in tools II and III.

- Reliabilities of tools II, III and IV were tested using Cronbach's alpha coefficient method on a sample of 15 outpatients who attending the clinic and 15 related family caregivers who meet the criteria of the study sample. Tools II, III and IV proved to be reliable ( $\alpha=0.88,0.91$ and 0.86 respectively).

- Outpatients' medical charts were reviewed to identify patients who meet the inclusion criteria and to check their socio-demographic and clinical data using tool I: part (1).

- All available patients diagnosed with psychotic disorders and their accompanying family caregivers who meet the inclusion criteria were recruited as the study subjects.

- Patients were interviewed in the outpatient clinic to assess their adherence to medication regimen using tool IV, and to complete their sociodemographic and clinical characteristics using tool I: part (1). These data were double checked with data collected from the patients' medical charts.

- Family caregivers who accompanied the recruited patients were interviewed to explore their socio-demographic and clinical characteristics and caregiving process using tool I: part (2), to elicit their attitudes toward both mental illness and psychotropic medications using tools II and III respectively, and to double check their patients' level of adherence using tool IV.

\section{Ethical considerations:}

- Informed written consent for voluntary participation in the study was obtained from the recruited patients and their family caregivers after explaining the aim of the study.

- Subjects' privacy and anonymity were assured and respected.

- Data confidentiality was considered and respected.

\section{Statistical Analysis}

- Collected data were coded and transferred into specially designed formats suitable for computer feeding.

- Data entry, checking and verification were carried out. Frequency analysis, cross-tabulation and manual revision were all used to detect any errors. 
- The Statistical Package for Social Sciences (SPSS) program, version 20.0 was utilized for both data presentation and statistical analysis of the results.

- The following statistical measures were used: frequency, percentage, minimum, maximum, arithmetic mean, and standard deviation were used.
A. For descriptive presentations
B. Fisher's Exact Test (FET) was used to test the association between variables when expected frequency $>5$ exceeding $20 \%$ of cells.

- Levels of significance selected for this study were $\mathrm{p}$ equal to or less than 0.05 and 0.001 .

\section{Results}

Table (1) presents the distribution of the studied family caregivers according to their socio-demographic characteristics. Caregivers were the patient's parents (34.0\%), siblings (32.0\%), spouses $(26.7 \%)$, or sons and daughters $(7.3 \%)$. It was noted that $71.3 \%$ of the patients' caregivers were females. Their age ranged between 18 and 66 years, with a mean age of $42.13 \pm 13.35$ years. The results reveal that the highest percentage of caregivers $(28.0 \%)$ aged between 18 to less than 30 years, while the lowest percentage of caregivers $(8.7 \%)$ aged between 60 years and 66 years. It was also found that $70.0 \%$ of caregivers were married, $17.3 \%$ were single, and $12.7 \%$ were divorced or widowers.

As for the caregivers' educational level, $45.3 \%$ of them had preparatory education, followed by those who were illiterate $(24.0 \%)$, and only $6.0 \%$ had university education. The greatest percentage of patients' caregivers $(60.7 \%)$ was housewives. More than one half of the caregivers $(56.0 \%)$ reported that their income was insufficient.
Table (2) shows the distribution of the studied family caregivers according to their clinical and caregiving characteristics. Concerning the family history of mental illness, around one half of caregivers $(51.3 \%)$ reported that they had positive family history of mental illness.

Regarding the action taken on the first appearance of patient's psychiatric symptoms, $70.0 \%$ of caregivers stated that they sought psychiatric help from a private psychiatrist or a psychiatric hospital, while $30.0 \%$ reported that they sought help from religious and traditional healers.

The results indicate that the duration of caregiving or being the only caregiver ranged between 8 months and 30 years, with a mean of $8.42 \pm 6.19$ years. The highest percentage of subjects $(32.7 \%)$ had a duration of caregiving for a year or less, while $7.3 \%$ of subjects were the only patient's caregiver for 20 years or more.

A percentage of $56.0 \%$ of the studied caregivers reported that they became carers because they wanted to help and support a loved one and $22.7 \%$ did that because of having a sense of responsibility and obligation to their ill relative, whereas $21.3 \%$ became caregivers just because of living with the patient in the same house.

The table also shows that $17.3 \%$ of caregivers were suffering from psychological problems, e.g., anxiety, insomnia and/or depressed mood. Out of them, $61.5 \%$ sought professional psychiatric help. This help was obtained from a psychiatrist $(87.5 \%)$ and/or a psychiatric nurse $(25.0 \%)$. Most of these caregivers $(88.5 \%)$ received psychotropic medications (prescribed or self-medication) to manage their own psychological problems.

Table (3) presents the distribution of the studied patients according to their sociodemographic characteristics. It was noted that $68.7 \%$ of the studied patients were males. Patients' age ranged between 20 and 72 years, with a mean age of $37.75 \pm 12.09$ years. Those aged 20 years to less than 30 years constituted more than one quarter 
(28.7\%), while patients aged 30 years to less than 40 years constituted more than one third $(39.3 \%)$ of the studied patients.

As for the marital status, single patients constituted $47.3 \%$, followed by married ones $(41.3 \%)$, and only $11.4 \%$ of patients were divorced or widowers. It was also found that $29.3 \%$ of patients had secondary or intermediate education, $24.7 \%$ were illiterate, and $21.3 \%$ had preparatory education. Those who only read and write and those who had primary education constituted $18.0 \%$, while only $6.7 \%$ of patients had university education.

In relation to the occupation, $34.0 \%$ of patients were manual workers and $28.0 \%$ were housewives. Unemployed patients constituted $20.0 \%$ of the studied subjects. The majority of the studied patients $(98.0 \%)$ were living in urban areas with their caregivers.

Table (4) shows the distribution of the studied patients according to their clinical characteristics. It was found that $72.0 \%$ of patients were diagnosed with schizophrenia, whereas $28.0 \%$ had mood disorders. The duration of illness ranged between 8 months and 35 years, with a mean of $11.75 \pm 8.61$ years. It was noted that the duration of illness for more than two fifths of patients $(41.3 \%)$ was less than or equal to 5 years.

Previously hospitalized patients constituted $79.3 \%$ of the studied subjects. The number of previous psychiatric hospitalization ranged between 1 and 15 times, with a mean of $3.82 \pm 3.48$. The time lapsed since last discharge ranged from 2 months to 8 years, with a mean of $2.10 \pm 2.19$ years. It was found that $31.1 \%$ of the studied patients discharged since less than 6 months. The results also reveal that $62.0 \%$ of patients were visiting the outpatient clinic accompanied by caregivers routinely for follow up and dispensing medication, while $38.0 \%$ of them were seeking the clinic to manage their psychotic relapse.

The table also lists the prescribed psychotropic medications for the studied patients as recorded in their medical charts. Typical antipsychotics was the most frequently prescribed group of psychotropic medications (74.0\%). From this percentage, oral medications were prescribed for $89.2 \%$, whereas intramuscular injections were prescribed for $42.3 \%$ of patients. Mood stabilizers and atypical antipsychotics were prescribed for $37.3 \%$ and $28.0 \%$ respectively of the studied patients. On the other hand, the least frequent prescriptions were novel and cyclic antidepressants $(9.3 \%$ and $8.0 \%$ respectively).

Table (5) shows the distribution of the studied family caregivers according to their attitudes towards mental illness (FAMI) and psychotropic medications (FAPM). It was found that caregivers had a mean score of $27.15 \pm 3.91$ on FAMI, with the majority of them $(93.3 \%)$ having positive attitude towards mental illness. On the other hand, caregivers' mean score on FAPM was $25.30 \pm 3.21$, with $85.3 \%$ demonstrating positive attitude towards psychotropic medications.

Figure (1) presents the distribution of the studied patients according to their adherence to medication regimen. A percentage of $64.7 \%$ of the outpatients reported that they were adherents, whereas $35.3 \%$ of patients reported that they were nonadherents to their medication regimens.

Table (6) illustrates the relationship between family caregivers' attitudes toward both mental illness (FAMI) and psychotropic medications (FAPM), and patient's adherence to medication regimen. It was noted that the percentages of caregivers who had positive attitudes on both FAMI and FAPM were the highest among patients who were adherents to medications $\quad(68.6 \%$ and $70.3 \%$ respectively). On the other hand, most of caregivers who had negative attitudes toward mental illness $(90.0 \%)$ and psychotropic medications $(68.2 \%)$ their patients reported being nonadherents to medications.

Fisher exact test detected statistically significant relationships between both 
FAMI ( $\mathrm{p}=0.0004)$ and FAPM $(\mathrm{p}=0.0012)$, and patient's medication adherence.

Table (7) displays the relationship between family caregivers' attitudes towards mental illness (FAMI) and their attitudes towards psychotropic medications (FAPM). It was noticed that $91.4 \%$ of the caregivers who had positive FAMI demonstrated positive FAPM compared to $8.6 \%$ for those who hold positive FAMI and negative FAPM, whereas all caregivers $(100.0 \%)$ with negative FAMI hold negative FAPM. A statistically significant relationship was evident between FAMI and FAPM $(\mathrm{FET}=5.529, \mathrm{p}=0.023)$.

\section{Discussion}

Numerous studies revealed that adherence to medication regimens is lower among individuals with psychotic disorders ${ }^{(9,10,13,14,27)}$. More specifically, it was reported that the prevalence of outpatients' nonadherence to psychotropic medications ranges from $40.3 \%$ to $58.8 \%{ }^{(26,30)}$. Yet, the present study revealed that nearly two thirds of the studied outpatients were adherents to their psychotropic medications. The same result was obtained by Edelman (2010) who observed that almost two thirds of the subjects reported full adherence to medication regimens ${ }^{(31)}$.

The present findings also revealed that the majority of the studied family caregivers hold positive attitudes toward both mental illness as measured by FAMI scale and psychotropic medications as measured by FAPM scale. These findings come in accordance with de Sousa et al. (2012) who noted that family caregivers had positive attitude toward the mental illness ${ }^{(32)}$. As well, caregivers in the study of Grover et al. (2014) had positive attitude toward psychotropic medications ${ }^{(23)}$. To the contrary, Elbur et al. (2014) concluded that the interviewed relatives had negatives attitudes towards patients and mental illness $^{(33)}$. In addition, Lazaratou et al. (2007) reported that parents have a negative opinion on psychotropic medications ${ }^{(24)}$.
Clinically, patient's adherent behavior does not develop in isolation. Rather, it was believed that a patients' willingness to adhere to medication regimen may reflect the attitudinal atmosphere in which it is proposed $^{(15,16)}$. The results of current study are in harmony with this belief where statistically significant relationships were detected between family caregivers' attitudes toward both mental illness and its medications, and patient's adherence. The studied caregivers whose patients were adherents demonstrated higher mean scores on both FAMI and FAPM than those whose patients were nonadherents to the prescribed medications regimens. Thus, it can be said that these attitudes significantly and positively impacted the studied patient's adherent behavior. Consistent with these results, previous studies found that attitudes of family members toward mental illness and psychotropics can influence patients' adherence and reactions toward these medications $^{(23,31)}$.

According to the results of the current study, the studied caregivers' attitudes toward both mental illness and psychotropic medications are not just related to patient's adherence, but also they are significantly related to each other. It was stated that favorable family caregivers' attitudes toward mental illness can be expressed by their belief in the effectiveness of medications $^{(34)}$. As a consequence, family caregivers who usually acknowledge the beneficial effect of medication on the clinical outcome of mental illness can motivate patients to take $\mathrm{it}^{(35)}$. On the other hand, if they have untoward attitudes, unpleasant feelings and poor perceptions of the illness, negative attitudes toward medications can result and in more extreme cases, these attitudes are sufficient enough for patients to discontinue their medication regimens $^{(36)}$.

By its very nature some psychotic disorders, such as schizophrenia, impair the insight and judgment, and place the patient at risk for medication nonadherence. Here, the caregivers' role is to help their relatives 
continue taking their medicines in order to maintain stability in the community. This can be done through continuous encouragement and reminders to ensure that medications are taken as prescribed ${ }^{(7,37)}$. However, the actions of family caregivers to promote adherence may go beyond mere encouragement $^{(38)}$. Actually, many caregivers play a supportive role in more practical ways by accompanying their patients for dispensing medications from the outpatient clinic. This is particularly true knowing that more than one half of the studied patients were visiting the outpatient clinic routinely accompanied by their family caregivers for follow up and dispensing the prescribed medication regimens. These caregivers' supporting and motivating behaviors reflect the positive attitude toward the patient and his mental illness and are perhaps of utmost powerful tools to carryout any long-term medication therapy ${ }^{(15,32)}$. In this context, it was argued that the patients' ability to manage their illness by adhering to the prescribed treatment program may be impaired without constant external support and motivation $^{(11,34)}$.

Caregivers' supportive actions and encouraging efforts cannot happen without positive attitudes toward their patient's mental illness. Only then, the patients' negative reactions to treatment can be reduced $^{(39)}$. In this respect, patients in the study of Teferra et al. (2013) mentioned lack of support from their family caregivers as one of the most important reasons for discontinuing treatment and follow up. Indeed, the respondents commented that adherence was impossible without the active involvement of their families ${ }^{(38)}$. Furthermore, Tesfay et al. (2013), found more than one half of the outpatients were nonadherents to medications due to poor social support from the family. This lack of support was associated not only with increasing risk of nonadherence, but also with irregular follow up ${ }^{(30)}$. In this way, social network of patients appears to be a valuable factor influencing the decision to take medication. It may also form an environmental pressure on the patient to take psychotropic medications $^{(13)}$.

It would seem worthwhile to mention here that more than one half of the studied caregivers in the present study reported that they became carers to help and support a loved one. Again, these findings place a great emphasis on the fundamental role of family caregivers' favorable attitudes on reinforcing medication adherence by setting a supportive caring actions involving medication giving. On the same line, various studies suggested that the availability of a supportive family caregiver to help patients manage their medications has been consistently shown to be associated with improved medication adherence $^{(19,34,37,40)}$.

Additionally, the current results revealed that the highest percentage of the studied caregivers (around one third) were the parents of the studied patients. These results may reflect the parents' greater involvement and responsibility for all the care of their ill child. Parents, as caregivers, usually reinforce patients' adherence by taking responsibility for obtaining, keeping and administering the medication and/or having patients' take it under their direct supervision. Through this close parentpatient relationship, more accepting reactions toward mental illness and medications are developed, and patient's adherence increases. Moreover, the results of the present study pointed out that females constituted the largest percentage of the studied caregivers. It was hypothesized that females are known to be the most often family caregivers who are involved in the care of their affected loved ones with a more tolerant attitude toward them ${ }^{(32)}$. Conversely, Caqueo-Urízar et al. (2011) found that the patients' mothers had the most rejecting and negative attitudes toward their patient's mental illness ${ }^{(18)}$.

Some other potential explanations of the statistically significant relationships between positive attitudes of the studied caregivers and patient's adherence may include the close personal contact of family 
caregivers with the patient. It is worth mentioning here that one of the main inclusion criteria of caregivers in the present study is to live with the patient in the same household. It has been believed that this daily personal contact with a relative who suffers from mental illness can result in a rich emotional experience which in turn can lead to accepting and empathetic attitudes toward the patient's mental illness $^{(41)}$. Furthermore, it was postulated that caregivers who live with the patient are more likely to be hopeful for a cure, exhibit fewer critical atmospheres toward the patient and develop an optimistic view of treatment, so they emphasize the patient's regular use of medications ${ }^{(34)}$. Conversely, it was claimed that the extended exposure of caregivers to the patients with psychosis resulted in negative attitudes towards both the patient and mental illness ${ }^{(18)}$.

The findings of the current study continue to reveal that most of the studied caregivers sought the psychiatric help from a private psychiatrist or a psychiatric hospital to manage patients' symptoms. This finding suggests that the actions taken by family caregivers on the onset of patient's psychiatric symptoms may shape their attitudes toward mental illness and consequently patient's adherence. In an attempt to explain this finding, the stigma of mental illness should be tackled here. It appears that the studied caregivers might view the mental illness and medications positively due to absence of stigma. Indeed, both stigma and denial of mental illness were reported as inhibitors to mental health services utilization and treatment. They may be harder to face and may lead caregivers to avoid everything connected with the illness and its treatment. Here, family caregivers are willing to seek traditional and religious advisors instead of seeking help from mental health professionals ${ }^{(42)}$. Some researchers noted that the stigma attached to mental illness is reflected on the family members and affects their reactions toward their patients' illness and treatment ${ }^{(24,43,44)}$. For these family caregivers, taking psychotropic medications means that they agree with the label of "crazy" or "psychotic", regardless of patient's symptoms relief and improved functioning as a result of taking medications regularly ${ }^{(34)}$.

Notably, the present findings indicated that more than one half of the studied caregivers reported that they had positive family history of mental illness. May be due to having past personal contact/experiences with mental illness, family caregivers are expected to be more willing to adopt nonstigmatizing and non-rejecting attitudes toward mental illness. Thus, caregivers accept the patient and his/her mental illness and believe that mental illness is treatable like any other illness. Previous exposure to serious and long-standing consequences of mental illness also empowered caregiver to face the illness and its stigma in their patients by seeking psychiatric treatment.

On the other hand, it seems that prior personal experience with mental illness, especially those with positive family history of mental illness, forced them to expect the negative consequences of untreated mental illness in the form of exacerbated psychotic symptoms. Therefore, these caregivers want to avoid psychotic relapse through controlling their relatives' florid symptoms by medications. Accordingly, these studied caregivers avoided religious and traditional healers and sought relief from the problems tied to mental illness by asking a professional help. This interpretation can be supported by the results of the present study where the greatest percentage of the studied caregivers accompanied their patients to the outpatient clinic for routine follow up and dispensing medications to prevent psychotic relapse. In this respect, Marquez and Ramírez García (2011) found caregivers' folk or indigenous beliefs about mental illness and treatment did not overrule their support of relatives' medication usage because they gave symptom stabilization a higher premium than their attitudes against medication $^{(19)}$.

Another possible explanation of the studied caregivers' positive attitude toward 
psychotropics and consequently patient's adherence might be the caregivers' own suffering from psychological problems and receiving psychotropic medication to manage these problems. Although the findings of the current study pointed out that the studied caregivers' caregivers who were suffering from psychological problems constituted a small percentage, out of this percentage, about three fifths sought professional psychiatric help either from a psychiatrist and/or a psychiatric nurse, and most of these caregivers received psychotropic medications to manage their own problems. Perhaps the caregivers' suffering from psychological problems makes them become more aware about the distressing symptoms of illness, understand how the patient feels and recognize the benefits of medication regarding symptom control and prevention of relapse. Thereby, it could be said that family caregivers' attitudes are influenced by their own experiences with mental illness and treating medications. In the same direction, it was pointed out that caregivers who had positive personal experiences about the fruitful effects of the medication can acknowledge that their relatives' behaviors or symptoms can improve in one way or another when they take medication ${ }^{(19)}$. When the caregiver views the patient's mental illness and psychotropic agents positively, has a positive personal experience with taking medications and shares these experiences with the patient, the patient's negative reactions can be reduced and adherence is probable being also treated with psychopharmacological agents ${ }^{(36,45)}$.

In contrast with prior studies ${ }^{(18,31)}$, the current study did not aim to investigate relationship between patients' and family caregivers' socio-demographic characteristics and caregivers' attitudes toward both mental illness and psychotropic medications. However, one can not deny that some clinical characteristics might indirectly contribute to such attitudes. For instance, the present results indicated that the duration of illness for more than two fifths of the studied patients was less than or equal to 5 years and near to one third of caregivers provided care for their patients for a year or less. In some ways, these relatively short durations might prevent caregivers from feeling bored with the chronicity of mental illness, long-term medication regimens and long duration of caregiving process, so caregivers' positive attitudes to the mental illness and psychotropic medications could be developed and consequently patient's adherence could be reinforced.

\section{Conclusion}

It can be concluded that patient's adherence is significantly related to family caregivers' attitudes toward mental illness and its medications. Hence, caregivers with positive attitudes toward mental illness and psychotropics tend to influence their patient's adherence and regular use of medication regimens.

\section{Recommendations}

In the light of the present findings, the following recommendations are suggested:

- Considering the relationship between family caregivers' attitudes and patients' adherence, assessment of their attitudes should be integrated and incorporated into the routine psychiatric nursing practice while developing the patient's plan of psychiatric treatment, so that prescribed regimens can be most effective.

- Family caregivers need to be involved while developing and implementing patient's adherenceenhancing nursing interventions.

- Further studies are required to study what factors can affect the family caregivers' attitudes toward mental illness and psychotropic medications, and consequently patient's adherence. 
Table (1): Distribution of the studied family caregivers according to their sociodemographic characteristics

\begin{tabular}{|c|c|c|}
\hline \multirow{2}{*}{$\begin{array}{l}\text { Family caregivers' socio-demographic } \\
\text { characteristics }\end{array}$} & \multicolumn{2}{|c|}{$(n=150)$} \\
\hline & No. & $\%$ \\
\hline \multicolumn{3}{|l|}{ Caregivers' kinship to the studied patients } \\
\hline Parent & 51 & 34.0 \\
\hline Sibling & 48 & 32.0 \\
\hline Spouse & 40 & 26.7 \\
\hline Son/daughter & 11 & 7.3 \\
\hline \multicolumn{3}{|l|}{ Sex } \\
\hline Female & 107 & 71.3 \\
\hline Male & 43 & 28.7 \\
\hline \multicolumn{3}{|l|}{ Age (in years) } \\
\hline $18-$ & 42 & 28.0 \\
\hline $30-$ & 34 & 22.7 \\
\hline $40-$ & 26 & 17.3 \\
\hline $50-$ & 35 & 23.3 \\
\hline $60+$ & 13 & 8.7 \\
\hline Min.-Max. & \multirow{2}{*}{\multicolumn{2}{|c|}{$\begin{array}{c}18-66 \text { years } \\
42.13 \pm 13.35 \text { years }\end{array}$}} \\
\hline Mean $\pm S D$ & & \\
\hline \multicolumn{3}{|l|}{ Marital Status } \\
\hline Single & 26 & 17.3 \\
\hline Married & 105 & 70.0 \\
\hline Divorced or widower & 19 & 12.7 \\
\hline \multicolumn{3}{|l|}{ Educational level } \\
\hline Illiterate & 36 & 24.0 \\
\hline Read and write \& Primary education & 19 & 12.7 \\
\hline Preparatory education & 68 & 45.3 \\
\hline Secondary or intermediate education & 18 & 12.0 \\
\hline University education & 9 & 6.0 \\
\hline \multicolumn{3}{|l|}{ Occupation } \\
\hline Housewife & 91 & 60.7 \\
\hline Manual worker & 16 & 10.7 \\
\hline Employee / professional & 15 & 10.0 \\
\hline Trader / Free business & 10 & 6.6 \\
\hline Student & 6 & 4.0 \\
\hline Unemployed & 12 & 8.0 \\
\hline \multicolumn{3}{|l|}{ Income } \\
\hline Insufficient & 84 & 56.0 \\
\hline Sufficient & 66 & 44.0 \\
\hline
\end{tabular}


Table (2): Distribution of the studied family caregivers according to their clinical and caregiving characteristics

\begin{tabular}{|c|c|c|}
\hline \multirow{2}{*}{ Family caregivers' clinical and caregiving characteristics } & \multicolumn{2}{|c|}{$(n=150)$} \\
\hline & No. & $\%$ \\
\hline \multicolumn{3}{|l|}{ Family history of mental illness } \\
\hline Positive & 77 & 51.3 \\
\hline Negative & 73 & 48.7 \\
\hline \multicolumn{3}{|l|}{$\begin{array}{l}\text { Action taken by caregivers on the onset of patient's } \\
\text { symptoms }\end{array}$} \\
\hline Seeking professional psychiatric help & 105 & 70.0 \\
\hline Seeking help from religious and traditional healers & 45 & 30.0 \\
\hline \multicolumn{3}{|l|}{ Duration of caregiving (in years) } \\
\hline$\leq 1$ & 49 & 32.7 \\
\hline$\overline{5}-$ & 40 & 26.7 \\
\hline $10-$ & 38 & 25.3 \\
\hline $15-$ & 12 & 8.0 \\
\hline $20+$ & 11 & 7.3 \\
\hline Min. $-\overline{M a x}$ & \multirow{2}{*}{\multicolumn{2}{|c|}{$\begin{array}{l}8 \text { months }-30 \text { years } \\
8.42 \pm 6.19 \text { years }\end{array}$}} \\
\hline Mean $\pm S D$ & & \\
\hline \multicolumn{3}{|l|}{ Reasons and circumstances of becoming a caregiver } \\
\hline Helping and supporting a loved one & 84 & 56.0 \\
\hline Sense of responsibility and obligation to my relative & 34 & 22.7 \\
\hline The patient lives with me in the same house & 32 & 21.3 \\
\hline \multicolumn{3}{|l|}{$\begin{array}{l}\text { Presence of caregivers' psychological problems as reported } \\
\text { by them }\end{array}$} \\
\hline Yes & 26 & 17.3 \\
\hline No & 124 & 82.7 \\
\hline \multicolumn{3}{|l|}{ Obtaining psychiatric help for their own problems } \\
\hline Yes & 16 & 61.5 \\
\hline No & 10 & 38.5 \\
\hline \multicolumn{3}{|l|}{ Personnel who provided the psychiatric help } \\
\hline Psychiatrist & 14 & 87.5 \\
\hline Psychiatric nurse & 4 & 25.0 \\
\hline \multirow{3}{*}{\begin{tabular}{|l} 
Receiving psychotropic medication to manage \\
psychological problems \\
Yes \\
No
\end{tabular}} & \multicolumn{2}{|c|}{$(\mathbf{n}=\mathbf{2 6})$} \\
\hline & 23 & 88.5 \\
\hline & 3 & 11.5 \\
\hline
\end{tabular}


Table (3): Distribution of the studied patients according to their socio-demographic characteristics

\begin{tabular}{|c|c|c|}
\hline \multirow{2}{*}{ Patients' socio-demographic characteristics } & \multicolumn{2}{|c|}{$(\mathbf{n}=150)$} \\
\hline & No. & $\%$ \\
\hline$\overline{\operatorname{Sex}}$ & & \\
\hline Male & 103 & 68.7 \\
\hline Female & 47 & 31.3 \\
\hline Age (in years) & & \\
\hline $20-$ & 43 & 28.7 \\
\hline $30-$ & 59 & 39.3 \\
\hline $40-$ & 28 & 18.7 \\
\hline $50+$ & 20 & 13.3 \\
\hline $\begin{array}{l}\text { Min. - Max. } \\
\text { Mean } \pm S D\end{array}$ & \multicolumn{2}{|c|}{$\begin{array}{l}20-72 \text { years } \\
37.75 \pm 12.09\end{array}$} \\
\hline Marital Status & & \\
\hline Single & 71 & 47.3 \\
\hline Married & 62 & 41.3 \\
\hline Divorced or widowers & 17 & 11.4 \\
\hline Educational level & & \\
\hline Illiterate & 37 & 24.7 \\
\hline Read and write \& primary education & 27 & 18.0 \\
\hline Preparatory education & 32 & 21.3 \\
\hline Secondary or intermediate education & 44 & 29.3 \\
\hline University education & 10 & 6.7 \\
\hline Occupation & & \\
\hline Manual worker & 51 & 34.0 \\
\hline Housewife & 42 & 28.0 \\
\hline Trader/Free business & 20 & 13.3 \\
\hline Student & 7 & 4.7 \\
\hline Unemployed & 30 & 20.0 \\
\hline Place of residence & & \\
\hline Urban & 147 & 98.0 \\
\hline Rural & 3 & 2.0 \\
\hline
\end{tabular}


Table (4): Distribution of the studied patients according to their clinical characteristics

\begin{tabular}{|c|c|c|}
\hline \multirow{2}{*}{ Patients' clinical characteristics } & \multicolumn{2}{|c|}{$(n=150)$} \\
\hline & No. & $\%$ \\
\hline \multicolumn{3}{|l|}{ Psychiatric diagnosis } \\
\hline Schizophrenia & 108 & 72.0 \\
\hline Mood disorders & 42 & 28.0 \\
\hline \multicolumn{3}{|l|}{ Duration of mental illness (in years) } \\
\hline 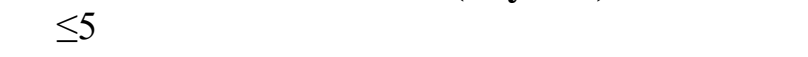 & 62 & 41.3 \\
\hline $10-$ & 39 & 26.0 \\
\hline $15+$ & 49 & 32.7 \\
\hline $\begin{array}{l}\text { Min. }- \text { Max } \\
\text { Mean } \pm S D\end{array}$ & \multicolumn{2}{|c|}{$\begin{array}{c}8 \text { months }-35 \text { years } \\
11.75 \pm 8.61 \text { years }\end{array}$} \\
\hline \multicolumn{3}{|l|}{ Previous psychiatric hospitalization } \\
\hline Yes & 119 & 79.3 \\
\hline No & 31 & 20.7 \\
\hline Number of previous psychiatric hospitalization & \multicolumn{2}{|c|}{$(n=119)$} \\
\hline Once & 18 & 15.1 \\
\hline Twice & 39 & 32.8 \\
\hline Triple & 25 & 21.0 \\
\hline Four times and more & 37 & 31.1 \\
\hline Min. - Max. & \multirow{2}{*}{\multicolumn{2}{|c|}{$\begin{array}{c}1-15 \text { Times } \\
3.82 \pm 3.48\end{array}$}} \\
\hline Mean $\pm S D$ & & \\
\hline Time lapsed since last discharge & \multicolumn{2}{|c|}{$(\mathrm{n}=119)$} \\
\hline$<6$ months & 37 & 31.1 \\
\hline 6 months - & 22 & 18.5 \\
\hline 1 year - & 31 & 26.1 \\
\hline 3 year + & 29 & 24.3 \\
\hline $\begin{array}{l}\text { Min. }- \text { Max. } \\
\text { Mean } \pm S D\end{array}$ & $\begin{array}{r}2 \mathrm{mon} \\
2.10 \\
\end{array}$ & $\begin{array}{l}\text { years } \\
\text { years }\end{array}$ \\
\hline \multicolumn{3}{|l|}{ Reason for visiting the outpatient clinic } \\
\hline Routine follow up and dispensing medication & 93 & 62.0 \\
\hline Psychiatric management of relapse & 57 & 38.0 \\
\hline \multicolumn{3}{|l|}{$\begin{array}{l}\text { Currently prescribed groups of psychotropic } \\
\text { medications }\end{array}$} \\
\hline Typical antipsychotics: & 111 & $\mathbf{7 4 . 0}$ \\
\hline - Oral & 99 & 89.2 \\
\hline - Intramuscular & 47 & 42.3 \\
\hline Mood stabilizers & 56 & 37.3 \\
\hline Atypical antipsychotics & 42 & 28.0 \\
\hline Novel antidepressants & 14 & 9.3 \\
\hline Cyclic antidepressants & 12 & 8.0 \\
\hline
\end{tabular}


Table (5): Distribution of family caregivers according to their attitudes towards mental illness (FAMI) and psychotropic medications (FAPM) $(n=150)$

\begin{tabular}{||l|c|c|c|c|c|c||}
\hline \multirow{2}{*}{$\begin{array}{l}\text { Family } \\
\text { caregivers' } \\
\text { attitudes }\end{array}$} & \multicolumn{2}{|c|}{$\begin{array}{r}\text { Positive } \\
\text { attitude } \\
\text { (Score: 21-40) }\end{array}$} & \multicolumn{2}{|c|}{$\begin{array}{r}\text { Negative } \\
\text { attitude } \\
\text { (Score: 0-20) }\end{array}$} & Min. - Max. & Mean \pm SD \\
\cline { 2 - 7 } & No. & $\%$ & No. & $\%$ & & \\
\hline FAMI & 140 & 93.3 & 10 & 6.7 & $16.0-38.0$ & $27.15 \pm 3.91$ \\
\hline FAPM & 128 & 85.3 & 22 & 14.7 & $12.0-39.0$ & $25.30 \pm 3.21$ \\
\hline
\end{tabular}

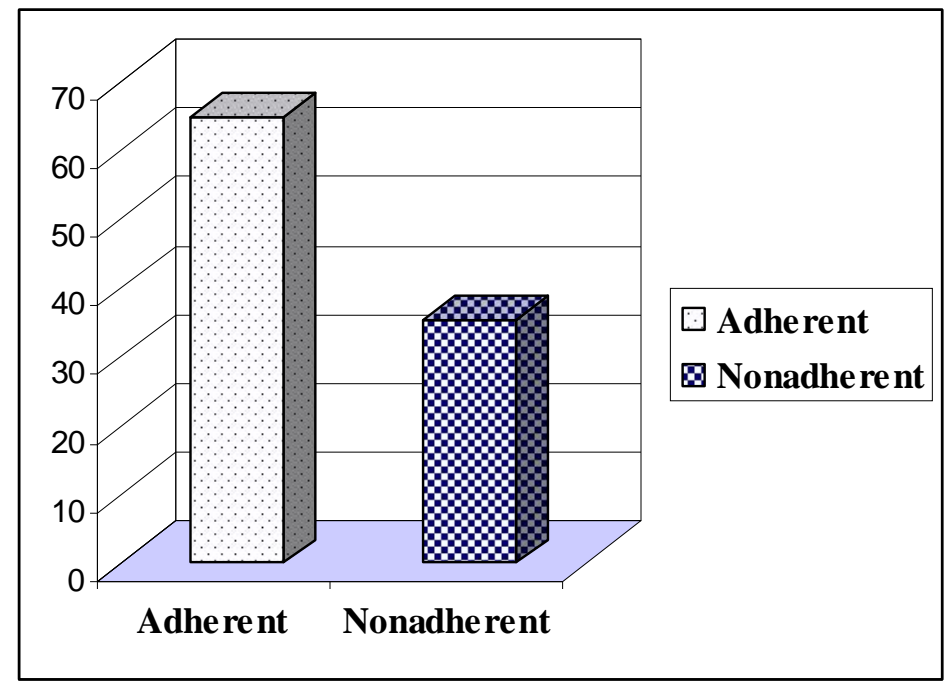

Figure (1): Distribution of the studied patients according to their adherence to medication regimen 
Table (6): Relationship between family caregivers' attitudes toward mental illness (FAMI) and psychotropic medications (FAPM), and patient's adherence $(n=150)$

\begin{tabular}{|c|c|c|c|c|c|c|c|c|}
\hline \multirow{3}{*}{$\begin{array}{l}\text { Medication adherence } \\
\text { as reported by the } \\
\text { patient }\end{array}$} & \multicolumn{4}{|c|}{ FAMI } & \multicolumn{4}{|c|}{ FAPM } \\
\hline & \multicolumn{2}{|c|}{$\begin{array}{l}\text { Positive } \\
\text { attitude } \\
(n=140)\end{array}$} & \multicolumn{2}{|c|}{$\begin{array}{l}\text { Negative } \\
\text { attitude } \\
(n=10)\end{array}$} & \multicolumn{2}{|c|}{$\begin{array}{l}\text { Positive } \\
\text { attitude } \\
(\mathrm{n}=128)\end{array}$} & \multicolumn{2}{|c|}{$\begin{array}{c}\text { Negative } \\
\text { attitude } \\
(\mathrm{n}=22)\end{array}$} \\
\hline & No. & $\%$ & No. & $\%$ & No. & $\%$ & No. & $\%$ \\
\hline Adherent (n=97) & 96 & 68.6 & 1 & 10.0 & 90 & 70.3 & 7 & 31.8 \\
\hline $\begin{array}{l}\text { Nonadherent }(\mathrm{n}=53) \\
\overline{F E T}\end{array}$ & 44 & 31.4 & 9 & 90.0 & 38 & 29.7 & 15 & 68.2 \\
\hline
\end{tabular}

FET: Fisher's Exact Test

*: Statistically significant value at $\mathrm{p} \leq 0.001$. 
Table (7): Relationship between family caregivers' attitudes towards mental illness (FAMI) and their attitudes towards psychotropic medications (FAPM) $((n=150))$

\begin{tabular}{|c|c|c|c|c|c|}
\hline \multirow{3}{*}{ FAPM } & \multicolumn{4}{|c|}{ FAMI } & \multirow{3}{*}{ Test of significance } \\
\hline & \multicolumn{2}{|c|}{$\begin{array}{c}\text { Positive } \\
\text { attitude } \\
\text { (Score:21-40) } \\
(\mathrm{n}=140)\end{array}$} & \multicolumn{2}{|c|}{$\begin{array}{c}\text { Negative } \\
\text { attitude } \\
\text { (Score:0-20) } \\
(\mathbf{n}=\mathbf{1 0})\end{array}$} & \\
\hline & No. & $\%$ & No. & $\%$ & \\
\hline $\begin{array}{l}\text { Positive attitude } \\
\text { (Score:21-40) } \\
(\mathrm{n}=128)\end{array}$ & 128 & 91.4 & 0 & 0.0 & $F E T=5.529 *$ \\
\hline $\begin{array}{l}\text { Negative attitude } \\
\text { (Score:0-20) } \\
(\mathrm{n}=22)\end{array}$ & 12 & 8.6 & 10 & 100.0 & $p=0.023$ \\
\hline
\end{tabular}

FET: Fisher's Exact Test

*: Statistically significant value at $\mathrm{p} \leq 0.05$. 


\section{References}

1. Novick D, Montgomery W, Treuer T, Aguado J, Kraemer S, Haro J. Relationship of insight with medication adherence and the impact on outcomes in patients with schizophrenia and bipolar disorder: results from a 1-year European outpatient observational study. BMC Psychiatry 2015; 15:189. Available at: http://www.biomedcentral.com/1471244X/15/189.pdf. (Retrieved on: 17/5/2016).

2. Antai-Otong D. Psychiatric nursing: Biological \& behavioral concepts. 2nd ed. New York: Delmar Learning, 2008.

3. Videbeck S. Psychiatric mental health nursing. 5th ed. Philadelphia: Lippincott Williams \& Wilkins Company, 2011.

4. Sadock B, Sadock V, Ruiz P. Kaplan and Sadock's synopsis of psychiatry: Behavioral science/clinical psychiatry. 11th ed. Philadelphia: Wolters Kluwer, 2014.

5. Mohr W. Psychiatric-mental health nursing: evidence-based concepts, skills, and practices. 7th ed. Philadelphia: Lippincott Williams\& Wilkins Company, 2009.

6. Chisholm-Burns M, Spivey C. Pharmacoadherence: a new term for a significant problem. American Journal of Health-System Pharmacy 2008; 65(7): 661-7.

7. Griffith T. Caregiver views on medication treatment for persons with schizophrenia in a cultural context. Published Doctoral Dissertation, School of Social Policy and Practice, University of Pennsylvania, 2012. Available at: http://repository.upenn.edu/cgi/viewcont ent.cgi?article $=1022 \&$ context $=$ edissertat ions_sp2. (Retrieved on: 22/6/2015).
8. Kemppainen J, Buffum M, Wike G, Kestnerv M, Zappe C, Hopkins R, Chambers K, Morrow M, Bartlebaugh P. Psychiatric nursing \& medication adherence. Journal of Psychosocial Nursing and Mental Health Services 2003; 41(2): 39-49.

9. Nosé M, Barbui C, Tansella M. How often do patients with psychosis fail to adhere to treatment programmes? A systematic review. Psychological Medicine 2003; 33(7): 1149-60.

10. Lingam R, Scott J. Treatment nonadherence in affective disorders. Acta Psychiatrica Scandinavica 2002; 105(3): 164-72.

11. Kampman O, Lehtinen $\mathrm{K}$, Lassila V, Leinonen E, Poutanen O, Koivisto A. Attitudes towards neuroleptic treatment: reliability and validity of the attitudes towards neuroleptic treatment (ANT) questionnaire. Schizophrenia Research 2000; 45(3): 223-34.

12. Pinikahana J, Happell B, Taylor M, Keks $\mathrm{N}$. Exploring the complexity of compliance in schizophrenia. Issues in Mental Health Nursing 2002; 23(5): 513-28.

13. Colom F, Vieta E. Non-adherence in psychiatric disorders: misbehavior or clinical feature? Acta Psychiatrica Scandinavica 2002; 105(3): 161-3.

14. Gurmu A, Abdela E, Allele B, Cheru E, Amogne B. Rate of nonadherence to antipsychotic medications and factors leading to nonadherence among psychiatric patients in Gondar University Hospital, Northwest Ethiopia. Advances in Psychiatry 2014. Available at: http://www.hindawi.com/journals/apsy/2 014/475812.pdf. (Retrieved on: 22/6/2015).

15. Mousa M. Factors affecting refusal of medications among hospitalized psychiatric patients. Unpublished Master 
Thesis: Faculty of Nursing, Alexandria University, 2006.

16. Kopelowicz A, Wallace C, Liberman R, Aguirre F, Zarate R, Mintz J. The use of the Theory of Planned Behavior to predict medication adherence in schizophrenia. Clinical Schizophrenia \& Related Psychoses 2007; 1(3): 227-242.

17. World Health Organization. WHO-aims report on mental health system in Egypt. $2006 . \quad$ Available at: http://www.who.int/mental health/evide nce/who_aims_report_egypt.pdf.

(Retrieved on: 22/6/2015).

18. Caqueo-Urízar A, Gutiérrez-Maldonado J, Ferrer-García M, Peñaloza-Salazar C, Richards-Araya D, Cuadra-Peralta A. Attitudes and burden in relatives of patients with schizophrenia in a middle income country. BMC Family Practice 2011; 12:101. Available at: http://www.biomedcentral.com/content/p df/1471-2296-12-101.pdf. (Retrieved on: 22/6/2015).

19. Marquez J, Ramírez García J. Family caregivers' monitoring of medication usage: a qualitative study of Mexicanorigin families with serious mental illness. Culture Medicine and Psychiatry 2011; 35(1): 63-82.

20. Crabb J, Stewart R, Kokota D, Masson N, Chabunya S, Krishnadas R. Attitudes towards mental illness in Malawi: a cross-sectional survey. BMC Public Health 2012; 12:541. Available at: http://www.biomedcentral.com/14712458/12/541.pdf. (Retrieved on: 25/7/2016).

21. Revilla C, Segura Y, Arrillaga G, Suárez B. Attitudes of the family toward the mentally ill patient. Actas Españolas de Psiquiatría 2010; 38(1): 58-65. Available at:

http://www.actaspsiquiatria.es/repositori o/11/61/ENG/11-61-ENG-57-64648959.pdf. (Retrieved on: 24/4/2016).
22. Sun B, Fan N, Nie S, Zhang M, Huang $\mathrm{X}$, He H, Rosenheck R. Attitudes towards people with mental illness among psychiatrists, psychiatric nurses, involved family members and the general population in a large city in Guangzhou, China. International Journal of Mental Health Systems; 2014; 8:26. Available at: http://www.ijmhs.com/content/8/1/26. (Retrieved on: 11/2/2016).

23. Grover S, Chakrabarti S, Sharma A, Tyagi S. Attitudes toward psychotropic medications among patients with chronic psychiatric disorders and their family caregivers. Journal of Neurosciences in Rural Practice 2014; 5(4): 374-383.

24. Lazaratou H, Anagnostopoulos D, Alevizos E, Haviara F, Ploumpidis D. Parental attitudes and opinions on the use of psychotropic medication in mental disorders of childhood. Annals of General Psychiatry 2007; 6(32). Available at: http://www.annals/general/psychiatry.co m/content/6/1/32. (Retrieved on: 24/4/2016).

25. Hogan T, Awad A, Eastwod R. A selfreport scale predictive of drug compliance in schizophrenics: reliability and discriminative validity. Psychological Medicine 1983; 13(1): 177-83.

26. Okpataku C, Kwanashie H, Ejiofor J, Olisah V. Medication compliance behavior in psychiatric out-patients with psychoactive substance use comorbidity in a Nigerian tertiary hospital. Nigerian Journal of Clinical Practice 2015; 18(3): 371-376.

27. Mousa M. The effect of "drug compliance therapy" on the compliance, attitude toward medication, and insight among hospitalized psychiatric patients. Unpublished Doctoral Thesis: Faculty of Nursing, Alexandria University, 2010. 
28. Kumar S, Sedgwick P. Can the factors influencing medication compliance reported from Western populations be applied to an eastern Indian context? Part I. Journal of Mental Health 2001; 10(3): 267-277.

29. Parashos I, Xiromeritis K, Zoumbou V, Stamouli S, Theodotou R. The problem of non-compliance in schizophrenia: opinions of patients and their relatives. A pilot study. International Journal of Psychiatry in Clinical Practice 2000; 4(2): 147-150.

30. Tesfay K, Girma E, Negash A, Tesfaye M, Dehning S. Medication nonadherence among adult psychiatric out patients in Jimma University Specialized Hospital, Southwest Ethiopia. Ethiopian Journal of Health Science 2013; 23(3): 227-236.

31. Edelman E. Patients' perception of family involvement and its relationship to medication adherence for persons with schizophrenia and schizoaffective disorders. Published Doctoral Dissertation, Graduate School-New Brunswick, Rutgers, the State University of New Jersey, 2010. Available at: http://ovidspnm.ovid.com.dlib.eul.edu.eg MuseSessionID=fe9d97cb98cee87cbad 6cc7be65bf84/MuseProtocol.pdf. (Retrieved on: 26/5/2016).

32. De Sousa S, Marques A, Curral R, Queirós C. Stigmatizing attitudes in relatives of people with schizophrenia: a study using the Attribution Questionnaire AQ-27. Trends in Psychiatry and Psychotherapy 2012; 34(4): 186-197.

33. Elbur A, Albarraq A, Yousif M, Abdallah M, Aldeeb I. Relatives' perception on mental illnesses, services and treatment, Taif, Saudi Arabia. World Journal of Pharmacy and Pharmaceutical Sciences 2014; 3(2): 969-980.
34. O'Brien P, Kennedy W, Ballard K. Psychiatric mental health nursing: an introduction to theory and practice. Sudbury: Jones and Bratlett Publishers, 2008.

35. Magliano L, Fiorillo A, De Rosa C, Malangone $\mathrm{C}$, Maj $\mathrm{M}$. Beliefs about schizophrenia in Italy: a comparative nationwide survey of the general public, mental health professionals, and patients' relatives. Canadian Journal of Psychiatry 2004; 49(5): 323- 331.

36. Fleischhacker W, Oehl M, Hummer M. Factors influencing compliance in schizophrenia patients. Journal of Clinical Psychiatry 2003; 64 (Suppl 16): 10-3.

37. Mibei F. Noncompliance to medication in psychiatric patients. Published Bachelor's Thesis, Nursing Program Degree, Turku University of Applied Sciences, 2013. Available at: https://theseus.fi/bitstream/handle/10024 169122/Noncompliance\%20To\%20Medi cation\%20In\%20Psychiatric\%20Patients .pdf. (Retrieved on: 12/9/2016).

38. Teferra S, Hanlon C, Beyero $\mathrm{T}$, Jacobsson L, Shibre T. Perspectives on reasons for non-adherence to medication in persons with schizophrenia in Ethiopia: a qualitative study of patients, caregivers and health workers. BMC Psychiatry 2013; 13:168. Available at: http://www.biomedcentral.com/1471244X/13/168.pdf. (Retrieved on: 12/9/2016).

39. Jin J, Sklar G, Oh V, Li S. Factors affecting therapeutic compliance: A review from the patient's perspective. Therapeutics and Clinical Risk Management 2008; 4(1): 269-286.

40. Ramírez García J, Chang C, Young J, López S, Jenkins J. Family support predicts psychiatric medication usage among Mexican American individuals with schizophrenia. Social Psychiatry 
and Psychiatric Epidemiology 2006; 41(8): 624-631.

41. Turner S. Reducing stigma toward the mentally ill: the impact of exposure versus information. Hanover College, 2007. Available at:

http://psych.hanover.edu/researchThesis07/TurnerPaper.pdf. (Retrieved on: $13 / 8 / 2015)$.

42. Boyd M. Psychiatric nursing: contemporary practice. 5th ed. Philadelphia: Wolters Kluwer, 2015.

43. Sajatovic M, Jenkins J. Is antipsychotic medication stigmatizing for people with mental illness?. International Review of Psychiatry 2007; 19(2): 107-12.
44. Hasson-Ohayon I, Levy I, Kravetz S, Vollanski-Narkis A, Roe D. Insight into mental illness, self-stigma, and the family burden of parents of persons with a severe mental illness. Comprehensive Psychiatry 2011; 52(1): 75-80.

45. Saenz D. A retrospective study of the correlation between diagnosis of schizophrenia or bipolar disorder and medication noncompliance. Published Doctoral Dissertation, West Virginia: West Virginia University, 1998. Available at: https://www.lib.wvu.edu/etd/1998/saenz 3546/saenz3546.pdf. (Retrieved on: 12/9/2016). 